http://jmscr.igmpublication.org/home/ ISSN (e)-2347-176x ISSN (p) 2455-0450

crossref DOI: https://dx.doi.org/10.18535/jmscr/v9i3.20

\title{
Pattern of disclosure of HIV status in children living with HIV in central India - A cross-sectional study
}

\author{
Authors \\ Dr Kanchan D. Ingle ${ }^{1}$, Dr Jyotsna Deshmukh ${ }^{2}$ \\ ${ }^{1}$ Assistant Professor, Department of Community Medicine, GMC Nagpur, Maharashtra, India \\ ${ }^{2}$ Associate Professor, Department of Community Medicine, IGGMC Nagpur, Maharashtra, India
}

\begin{abstract}
Background: Human Immunodeficiency Virus (HIV) disclosure to infected children and adolescents is very essential for maintaining personal health and for prevention of HIV within the larger population. HIV non-disclosure has been identified as one of the potential barriers to optimum adherence especially in children and adolescents ${ }^{[1]}$.There has been a significant increase in the survival of HIV infected children with the advent of antiretroviral therapy (ART). But, HIV status disclosure to children remains a complex and a critical clinical issue in the care of HIV-infected children ${ }^{[2]}$.

Methodology: A hospital-based cross-sectional study was conducted at the ART centre of tertiary care hospital in central India from June 2017 to May 2018. Caregivers of HIV positive children $\leq 15$ years of age and on antiretroviral therapy were interviewed and data regarding asocio-demographic variables and pattern of disclosure of HIV status was obtained using a pre tested, structured questionnaire.

Result: We found that maximum caregivers were parents and HIV status ware informed by 105(44.70\%) caregivers only. 131(55.70\%) of caregivers were not sure about the appropriate age for HIV status disclosure. The main reason for not disclosing HIV status to children was that the child was too young to disclose. Statistically significant association present between socioeconomic status and by caregivers and also between education of caregivers and pattern of disclosure.

Conclusion: More than 50\% of children were not informed about their HIV status by caregivers. The main reason for not disclosing HIV status to children was that the child was too young to disclose followed by 'due to feelings of guilt'.

Keywords: HIV, disclosure, caregivers.
\end{abstract}

\section{Introduction}

Human immunodeficiency virus infection is one of the most challenging diseases in the present era ${ }^{[3]}$. Of the estimated 38.0 million people living with HIV worldwide in 2019, 2.8 million [1.9-3.7 million] were children aged 0-19. Each day in 2019, approximately 880 children became infected with HIV and approximately 310 children died from AIDS related causes, mostly because of inadequate access to HIV prevention, care and treatment services $^{[4]}$. Children are not only personally affected by HIV/AIDS, but also affecting their families and their right to parental care and affection. UNICEF finds that the infection can lead children to drop out of school; infection of parents can lead children to engage in child labour in order to survive ${ }^{[6]}$.

Stigma is a major barrier to the disclosure of HIV status to children. Caregivers fear that children will face stigma. This fear often delays their decisions to 
disclose. The word "stigma" is derived from the Greek word for "brand" or "mark". This "mark" was associated with a lower position in life and was characterized by fear and shunning by others, often leading to feelings of unworthiness in the person being stigmatized ${ }^{[5]}$.

Disclosure is crucial to the continuum of HIV care. The lack of HIV status disclosure ultimately adversely affects the well-being, treatment, and care of children. So, this study aims to study the pattern of disclosure of HIV status in children living with HIV.

\section{Methodology}

A hospital-based cross-sectional study was conducted at the ART centre of tertiary care hospital in central India from June 2017 to May 2018.. The caregiver of HIV positive children $\leq 15$ years of age and on antiretroviral therapy were interviewed and data regarding a Pattern of disclosure of HIV status was obtained with a questionnaire on disclosure pattern based on Guidelines on HIV disclosure counselling for children.

The sample size calculation was done considering the precent of caregivers $(80.6 \%)$ lacked disclosure knowledge on how and what to tell a child ${ }^{[1] .}$ Taking this value as reference, the minimum required sample size with a 5\% level of significance came out to be 235.Caregivers were enrolled in the study using a convenience sampling. Before starting the interview, caregivers were well informed about the nature of the study. The confidentiality of the caregivers was assured and maintained throughout the study. All the interviews were carried out by the same investigator to avoid interobserver variability and the number of caregivers interviewed was restricted to 2-3 per recruitment day. The interview was carried out in a separate room ensuring privacy for the interviewee and the responses were recorded in the questionnaire.

Definitions- Disclosure ${ }^{[6]}$ : Where the caregiver said that the child knows his/her HIV diagnosis.

Non-disclosure $^{[6]}$ : Where the caregiver said that the child does not know his/her infection or where the caregiver was unsure if the child knew his/her status.
Partial disclosure $^{[7]:}$ It is the term used for describing situations in which children are given some but not all information about their illness.

Caregiver $^{[6]}$ : A person, who lives with the child, participates in the child's daily care, and is the most knowledgeable about the child's health. They were either biological parents or guardians acting as surrogate parents to the child.

Stigma $^{[8]}$ : It is defined as a simplified, standardized image of the disgrace of certain people that are held in common by the community at large.

Data Analysis: Data were cleaned, coded and captured on Microsoft Excel and analysed using statistical packaging for social sciences (SPSS) software version 21. The data was presented through tables and frequency distributions. Categorical variables were presented in number and percentage (\%). Qualitative variables were correlated using Chi-Square test/Fisher's exact test. A $p$ value of $<0.05$ was considered statistically significant.

Ethical Considerations: Permission was gained from the institutional ethics committee, where the study was conducted. Confidentiality was ensured at all stages of the process. Data collection was preceded by an informed consent signed by participants.

\section{Results}

Socio-demographic and economic characteristics. In 235 caregivers, 92(39.15\%) were fathers of children, $79(33.62 \%)$ were mothers of children and 64(27.23\%) were second degree relatives (it includes uncle, aunt, grandparents).

All 235 caregivers were literate. Out of them 49 $(20.86 \%)$ were educated up to secondary class followed by postgraduate and above education in $43(18.29 \%)$ caregivers, $41(17.45 \%)$ caregivers were educated up to primary class, $38(16.17 \%)$ caregivers were undergraduate. $37(15.74 \%)$ were educated up to senior secondary and $27(11.48 \%)$ had education up to upper Primary [61].

In 235 caregivers, $73(31.0 \%)$ of caregivers belonged to class III and, an equal number of caregivers 
$57(24.3 \%)$ from class IV and class V. 31 (13.2\%) caregivers were from class II and a very few 17 $(7.2 \%)$ in class I of socioeconomic status (BGP).

Table 1: Distribution of caregivers according to the pattern of disclosure of HIV status to children.

\begin{tabular}{|l|c|c|}
\hline $\begin{array}{l}\text { Pattern of disclosure of HIV } \\
\text { status by caregiver* }\end{array}$ & Number & $\%$ \\
\hline Informed & 105 & 44.70 \\
\hline Misinformed & 27 & 11.50 \\
\hline Non-Informed & 103 & 43.80 \\
\hline Total & 235 & 100.0 \\
\hline
\end{tabular}

*Pattern of disclosure of HIV status by caregiver ${ }^{[5]}$.

Table 1 shows the distribution of caregivers according to pattern of disclosure of HIV status to children. Out of 235 caregivers, HIV status was informed by $105(44.70 \%)$ caregivers, 27 (11.50\%) caregivers misinformed children about their HIV status and $103(43.80 \%)$ caregivers didn't inform HIV status to children.

Table 2: Distribution of caregivers according to their responses about the pattern of disclosure of HIV status to children.

\begin{tabular}{|l|c|c|c|}
\hline *Responses of caregivers & Number & \% \\
\hline $\begin{array}{l}\text { Does the child } \\
\text { know about the } \\
\text { status? }\end{array}$ & No & 130 & 55.30 \\
\cline { 2 - 4 } & $10-15 y r s$ & 105 & 44.70 \\
\hline $\begin{array}{l}\text { Appropriate age for } \\
\text { HIV status } \\
\text { disclosure }\end{array}$ & $5-10 y r s$ & 18 & 36.60 \\
\cline { 2 - 4 } & Not sure & 131 & 5.70 \\
\hline
\end{tabular}

\begin{tabular}{|c|c|c|c|c|}
\hline \multirow{3}{*}{\multicolumn{2}{|c|}{$\begin{array}{lr}\text { Best person for } \\
\text { disclosing HIV } \\
\text { status to a child }\end{array}$}} & Doctor & 23 & 9.80 \\
\hline & & Family members & 31 & 13.20 \\
\hline & & Parents & 181 & 77.00 \\
\hline \multirow{7}{*}{\multicolumn{2}{|c|}{$\begin{array}{l}\text { Reasons for not } \\
\text { disclosing }\end{array}$}} & Disclosed & 105 & 44.70 \\
\hline & & $\begin{array}{c}\text { Fear of social } \\
\text { stigma in case the } \\
\text { child told someone } \\
\text { else }\end{array}$ & 14 & 6.00 \\
\hline & & Feeling of guilt & 21 & 8.90 \\
\hline & & $\mathrm{He} / \mathrm{she}$ is too young & 55 & 23.40 \\
\hline & & $\begin{array}{l}\mathrm{He} / \text { she will become } \\
\text { mentally disturbed }\end{array}$ & 7 & 3.00 \\
\hline & & $\begin{array}{l}\mathrm{He} / \text { she will hate his } \\
\text { parents }\end{array}$ & 9 & 3.80 \\
\hline & & $\begin{array}{c}\text { There is no need to } \\
\text { disclose }\end{array}$ & 24 & 10.2 \\
\hline \multirow{5}{*}{\multicolumn{2}{|c|}{$\begin{array}{l}\text { Advantages } \\
\text { disclosure }\end{array}$}} & $\begin{array}{c}\text { Better adherence to } \\
\text { ART }\end{array}$ & 17 & 7.20 \\
\hline & & $\begin{array}{l}\text { Better parent-child } \\
\text { communication }\end{array}$ & 23 & 9.80 \\
\hline & & Better self-care & 32 & 13.60 \\
\hline & & $\begin{array}{l}\text { He/she will collect } \\
\text { medicines himself } \\
\text { from the clinic }\end{array}$ & 14 & 6.00 \\
\hline & & None & 149 & 63.40 \\
\hline \multirow{3}{*}{\multicolumn{2}{|c|}{$\begin{array}{l}\text { Disadvantages of } \\
\text { disclosure }\end{array}$}} & $\begin{array}{l}\mathrm{He} / \text { she will become } \\
\text { depressed/anxious }\end{array}$ & 42 & 17.90 \\
\hline & & $\begin{array}{l}\mathrm{He} / \text { she will start } \\
\text { resenting his }\end{array}$ & 71 & 30.20 \\
\hline & & None & 122 & 51.90 \\
\hline \multicolumn{5}{|c|}{$\begin{array}{l}\text { *responses of caregivers regarding the pattern of } \\
\text { disclosure of HIV status }{ }^{[9]} \text {. }\end{array}$} \\
\hline \multicolumn{5}{|c|}{ economic status and pattern of disclosure. } \\
\hline \multicolumn{2}{|c|}{ Misinformed } & \multicolumn{3}{|c|}{ Not informed } \\
\hline & $\%$ & \begin{tabular}{|l|} 
No. \\
\end{tabular} & & \\
\hline & 0 & 12 & & \\
\hline & 35.50 & 11 & & \\
\hline & 2.70 & 34 & & \\
\hline & 14.04 & 21 & & \\
\hline & 10.53 & 25 & & \\
\hline & 11.50 & 103 & & \\
\hline
\end{tabular}

Table 3: Distribution of caregivers according to socioeconomic status and pattern of disclosure.

\begin{tabular}{|c|c|c|c|c|c|c|}
\hline \multirow[t]{2}{*}{ Socioeconomic status } & \multicolumn{2}{|c|}{ Informed } & \multicolumn{2}{|c|}{ Misinformed } & \multicolumn{2}{|c|}{ Not informed } \\
\hline & No. & $\%$ & No. & $\%$ & No. & $\%$ \\
\hline $\mathrm{I}(\mathrm{n}=17)$ & 5 & 29.40 & 0 & 0 & 12 & 70.60 \\
\hline II $(n=31)$ & 9 & 29.00 & 11 & 35.50 & 11 & 35.50 \\
\hline III $(n=73)$ & 37 & 50.70 & 2 & 2.70 & 34 & 46.60 \\
\hline IV $(n=57)$ & 28 & 49.12 & 8 & 14.04 & 21 & 36.84 \\
\hline $\mathrm{V}(\mathrm{n}=57)$ & 26 & 45.61 & 6 & 10.53 & 25 & 43.86 \\
\hline Total (235) & 105 & 44.70 & 27 & 11.50 & 103 & 43.80 \\
\hline
\end{tabular}

\begin{tabular}{|c|c|c|c|c|c|c|c|}
\hline \multirow[t]{2}{*}{ Education } & \multirow[b]{2}{*}{$\mathrm{N}$} & \multicolumn{2}{|c|}{ Informed } & \multicolumn{2}{|c|}{ Misinformed } & \multicolumn{2}{|c|}{ Not informed } \\
\hline & & No. & $\%$ & No. & $\%$ & No. & $\%$ \\
\hline Illiterate & 10 & 8 & 80.00 & 1 & 10.00 & 1 & 10.00 \\
\hline Primary( I to V) & 38 & 25 & 65.80 & 5 & 13.10 & 8 & 21.10 \\
\hline Upper primary(VI to VIII) & 27 & 5 & 18.50 & 3 & 11.10 & 19 & 70.40 \\
\hline Secondary (IX to X) & 42 & 17 & 40.50 & 3 & 7.10 & 22 & 52.40 \\
\hline Senior secondary(XI to XII) & 37 & 30 & 81.10 & 2 & 5.40 & 5 & 13.50 \\
\hline Undergraduate & 38 & 10 & 26.30 & 2 & 5.30 & 26 & 68.40 \\
\hline Postgraduate and above & 43 & 10 & 23.26 & 11 & 25.58 & 22 & 51.16 \\
\hline Total & 235 & 105 & 44.7 & 27 & 11.5 & 103 & 43.8 \\
\hline
\end{tabular}


Table 2 depicts the distribution of caregivers according to pattern of disclosure of HIV status to children. As per the response given by caregivers, $105(44.70 \%)$ children knew their status, and 130 $(55.30 \%)$ were not aware of their status. Out of 235 caregivers, $86(36.60 \%)$ of caregivers thought that the preferred age of disclosure was 10 to 15 years, $18(7.70 \%)$ were of the opinion that disclosure should be made between 5 to 10 years of age group. Over half, 131(55.70\%) were not sure about the appropriate age for HIV status disclosure.

According to the caregiver's response, parents were the best person for disclosing HIV status in $181(77.00 \%)$ children, followed by family members in $31(13.20 \%)$ and health professionals in 23 $(9.80 \%)$ children.

The main reason for not disclosing HIV status to children was that the child was too young to disclosed in 55(23.40\%), 21 (8.90\%) of caregiver did not disclose the HIV status due to feeling of guilt, 14(6.00\%) caregiver had a fear that the child would tell others and the family might be stigmatized, the child would become mentally disturbed and would hate his parents was the reason for non-disclosure in $7(3.00 \%)$ and $9(3.80 \%)$ respectively. In 24(10.20\%) caregivers though there was no need to disclose the HIV status to the child.

Nearly $149(63.40 \%)$ of caregivers felt there were no benefits in telling the child her/his HIV status. The most commonly cited advantages of disclosure were that the child would be able to take better selfcare by $32(13.60 \%)$ caregivers, the disclosure would improve parent-child communication and adherence to treatment was advantage stated by 23 $(9.80 \%)$ and $17(7.20 \%)$ caregivers respectively. $14(6.00 \%)$ of caregivers thought the child would collect medicines himself/herself from the clinic.

Around half, 122(51.90\%) of caregivers felt there were no disadvantages in disclosing HIV status. The most common disadvantage felt for disclosure that the child would start resenting his parents $71(30.20 \%)$ and would suffer emotional trauma and become depressed or anxious $42(17.90 \%)$.

Table 3 depicts the distribution of caregivers according to socioeconomic status and pattern of disclosure. The number of caregivers who did not inform children about their status was more $(70.60 \%)$ in socioeconomic class I and lower in socioeconomic class IV (36.8\%) and class V (43.9\%). Around $45.61 \%$ of caregivers from socioeconomic class $\mathrm{V}$ informed children about their status.Caregivers who did not inform (misinformed + not informed ) children about their HIV status were more in higher socioeconomic class (class I +class II) when compared with a low socioeconomic class (class III + class IV + class V) and this was found to be statistically significant. $\left(\square^{2}\right.$ value $=5.87, \mathrm{p}$-value $\left.=0.015, \mathrm{df}=1\right)$.

Table 4 shows the distribution of caregivers according to the education and pattern of disclosure to children. More number of caregivers who informed children about their HIV status were illiterate and senior secondary educated. As the Level of education increases; the number of caregivers not informed to children about their HIV status were also increased Significantly more number of caregivers who informed children about their HIV status were illiterate when compared with educated. (Fisher exact test, p-value $=0.04$, df 1).

\section{Discussion}

The global burden of paediatric HIV and acquired immune deficiency syndrome (AIDS) remains a challenge for healthcare workers around the world, particularly in developing countries.

A study conducted by Peter Mumburi et al ${ }^{[10]}$, Verma D et al ${ }^{[11]}$, Madiba $S$ et al ${ }^{[12]}$, and Gyamfi et $\mathbf{a l}^{[13]}$ reported similar results to our study finding that the majority of caregivers were parents (mother and father) of children. Verma $D$ et al observed that mother was the primary caregiver in almost twothirds of the children but in our study, a slightly higher number of study subjects had fathers as their caregiver as compared to mothers. Madiba $S$ et al found, $38.9 \%$ were the biological mothers, $30.1 \%$ were grandparents, and $30.7 \%$ were other relatives. Similarly, a study by Gyamfi et al shows, most of the caregivers $47.5 \%$ were the child's biological mother followed by grandparent $31(26.3 \%)$, $22(18.6 \%)$ were others and $9(7.6 \%)$ were fathers. 
Madiba S et al $^{[12]}$ observed that 163(40.2\%) caregivers had secondary education which was twice than our finding. They also found that $98(24.1 \%)$ caregivers had primary education which was slightly higher than our study finding. 69(17\%) caregivers completed education up to twelfth which was almost similar to our study finding and in contrast to our they found $60(14.8 \%$ ) had no education. The highest level of education of more than half $(64.6 \%)$ was that of a primary school and above, this finding of $\mathbf{P}$ Oberdorfer et $\mathbf{a l}^{[14]}$ is in consistence with our study. No caregiver was illiterate in our study but in contrast to our findings they observed that $6.1 \%$ had never attended any school. Gyamfi et al ${ }^{[13]}$ observed, only $3.4 \%$ of them had a tertiary level education which was found to be very less than what we have observed. A study by $\mathbf{V a z}$ et al $^{[15]}$ was in concordance with our study that $37(18 \%)$ completed secondary school and only $3(1 \%)$ had no education.

A study conducted by Thakor et al ${ }^{[16]}$ found, majority of children 51(56.7\%) belonged to social class IV (according to modified Prasad's social classification). In contrast to our findings Henry Chineme Anyabolu et al $^{[17]}$ found, there were more of the infected children in the lower socioeconomic class. A study conducted by Verma D et $\mathbf{a l}^{[11]}$ found, majority $(67.3 \%)$ belonged to upper lower socio-economic class.

Peter Mumburi et al ${ }^{[10]}$ found slightly higher percentage than our study where, majority 122 $(53.1 \%)$ of children had their serostatus undisclosed to them while nearly a quarter i.e. 52(24.6\%) had partial disclosure and only 47 (22.3\%) had complete disclosure and also reported a higher percentage of $41(19.4 \%)$ parents/caregivers preferred disclosure to happen between 6-9 years, while 170 (80.6\%) preferred disclosure to happen between 10-16 years. And also observed slightly lower percent $138(65.4 \%)$ of parents/caregiver indicated that the parent or caregiver alone should disclose about the illness to the child, while higher number of caregiver $60(28.4 \%)$ preferred healthcare providers to disclose the HIV-status to the child and 5 (2.4\%) caregivers indicated that anyone can do it. Gyamfi et al $^{[13]}$ noted, majority $66.7 \%$ of the children had not been told their HIV positive status which was higher than our study finding. Lorenz et $\mathbf{a l}^{[18]}$ found, $65 \%$ children were informed of their HIV status and $42 \%$ of caregivers admitted that they were misinformed to the child that they were sick with a disease other than HIV compared to our study greater number were informed and misinformed and the preferred age of disclosure of HIV status between the ages of 5 and 9 years. Madiba $S$ et al [12] reported, $111(27.4 \%)$ of the children were informed about their HIV diagnosis which was lower than our study finding and also found, $154(52.7 \%)$ caregivers thought that disclosure should be made between 10 and 14 years of age, which was higher than our finding and 15 (5.1\%) felt that disclosure should be made before 10 years of age which was approximately similar to our finding. And also reported 49(46.4\%) of caregivers preferred to disclose the HIV status to children themselves, which was lower than our study finding and $62(19.8 \%)$ thought that the health providers should disclose which was more than our study finding.

Similar to our finding Madiba $\mathbf{S}$ et $\mathbf{a l}^{[12]}$, Gyamfi et $\mathbf{a l}^{[13]}$ and Peter Mumburi et al ${ }^{[10]}$ observed that 'child was too young' was the main reason for not disclosing HIV status to children. Madiba $\mathbf{S}$ et $\mathbf{a}^{\mathrm{I}[12]}$ observed, $21(7.1 \%)$ caregiver thought that the child would tell others and the family might be stigmatized this was approximately similar to our finding, the child would experience negative reactions to disclosure was reason given by $24(8.2 \%)$ caregiver which was higher to our finding. They also found some other reasons than our study like, the child would not understand what HIV is all about, the child would harm him/herself and commit suicide, the child would think he/she was different from others and self-stigmatize, and caregiver lack of disclosure skills. Also observed, most caregivers disclosed because they believed that the child has a right to know the status, more number $26(35.1 \%)$ of caregiver said benefits of disclosure was to improve treatment adherence compare to our study finding. Another advantage was to prevent the child from 
infecting others. In contrast to our finding Peter Mumburi et al ${ }^{[10]}$ noted higher percentage of caregiver $50(30.5 \%)$ thought disclosure may cause negative emotional consequences like discrimination and $28(17.1 \%)$ caregiver said the child may not be able to keep it secret. 15 (9.1\%) caregivers did not know what and how to deliver the disclosure message.

In the present study, significantly more study subjects from higher socioeconomic status were not informed about their HIV status as compared to low socioeconomic status. While, Kallem s et al $^{[20]}$ observed, household income was not significantly associated with disclosure of HIV status to the child. In our study, significantly more number of illiterate caregivers were informed about a child's HIV status when compared with the educated. Kallem s et al ${ }^{[20]}$ found that education attainment of caregiver was not significantly associated with disclosure of HIV status to the child. Madiba $\mathbf{S}$ et al $^{[12]}$ reported, caregivers who had primary education were three times more likely to disclose than those who did not have any formal education. A. Binagwaho et al ${ }^{[19]}$ reported similar results to our study that Parents'/caregivers' education levels were inversely associated with HIV disclosure.

\section{Conclusion}

More than $50 \%$ of children were not informed about their HIV status by a caregivers. Half of caregivers were not sure about the appropriate age for HIV status disclosure. As per the caregiver's response, parents were the best person for disclosing HIV status. The main reason for not disclosing HIV status to children was that 'the child was too young to disclose followed by 'due to feelings of guilt'. Around two-third number of caregivers felt there were no benefits in telling the child her/his HIV status and the most common disadvantage for disclosure was, the child would start resenting his parents. Significantly more proportion of Illiterate caregivers informed about the HIV status to children when compared with educated and significantly more caregivers belonging to lower socioeconomic class had informed about HIV status to children compared to higher socioeconomic class.

\section{Recommendation}

We found $55.30 \%$ of study subjects were not informed about their HIV status by a caregiver because of feelings of guilt and fear of social stigma. So, strengthening of the IEC activity more, with a focus towards eliminating the stigma \& discrimination regarding HIV. In preparing for full disclosure, parents/caregivers and health workers need to help children manage the stigma of being infected or affected by HIV. There is a need to develop region specific paediatric HIV disclosure guidelines keeping in mind the caregivers' perceptions. The guidelines must be age appropriate, systematic, and socioculturally acceptable.

\section{Acknowledgement}

The authors gratefully acknowledge the participants and faculties at Department of Community Medicine, IGGMC, Nagpur for assistance and support.

Funding: No funding sources.

Conflict of interest: None declared.

\section{References}

1. Hayfron-Benjamin A, Obiri-Yeboah D, Ayisi-Addo S, Siakwa PM, Mupepi S. HIV diagnosis disclosure to infected children and adolescents; Challenges of family caregivers in the Central Region of Ghana. BMC Pediatr. 2018;18[1]:1-11.

2. Kallem S, Renner L, Ghebremichael M, Paintsil E. Prevalence and pattern of disclosure of HIV status in HIV-infected children in Ghana. AIDS Behav [Internet]. 2011 Aug [cited 2020 Dec 23];15[6]:1121-7. Available

from: /pmc/articles/PMC2989337/?report=abstract

3. Poudel P, Pokharel R, Chitlangia M, Chaudhary S. Profile of HIV infected children: A hospital based study at Eastern Nepal. Asian Pacific J Trop Dis. 
2014;4[3]:169-75.

4. HIV Statistics - Global and Regional Trends - UNICEF DATA [Internet]. [cited 2020 Dec 23]. Available from: https://data.unicef.org/topic/hivaids/globalregional-trends/

5. WHO. Guideline on $\{$ HIV $\}$ Disclosure $\}$ \{Counselling $\}$ for $\{$ Children $\{\mathrm{Up}\}$ to 12 \{Years $\}$ of $\{$ Age $\}$. Guideline [Internet]. 2011;46. Available from: http://www.ncbi.nlm.nih.gov/books/NBK30 4307/

6. Kallem S, Renner L, Ghebremichael M, Paintsil E. Prevalence and pattern of disclosure of HIV status in HIV-infected children in Ghana. AIDS Behav. 2011;15[6]:1121-7.

7. Wiener L, Mellins CA, Marhefka S, Battles HB. Disclosure of an HIV diagnosis to children: History, current research, and future directions. J Dev Behav Pediatr. 2007;28[2]:155-66.

8. Smith R, Rossetto K, Peterson BL. A metaanalysis of disclosure of one's HIV-positive status, stigma and social support. AIDS Care - Psychol Socio-Medical Asp AIDS/HIV. 2008;20[10]:1266-75.

9. Bhattacharya M, Dubey AP, Sharma M. Patterns of diagnosis disclosure and its correlates in HIV-infected north Indian children. J Trop Pediatr. 2011;57[6]:405-11.

10. Mumburi LP, Hamel BC, Philemon RN, Kapanda GN, Msuya LJ. Factors associated with HIV-status disclosure to HIV-infected children receiving care at Kilimanjaro Christian Medical Centre in Moshi, Tanzania. Pan Afr Med J. 2014;18:1-8.

11. Verma D, Acharya AS, Bachani D, Seth A. Clinico-Social and Immunological Profile of Antiretroviral Naïve Children Living With HIV In Tertiary Care Hospital, Delhi. SAARC J Tuberc Lung Dis HIV/AIDS [Internet]. 2017;13[1]:32. Available from: http://www.nepjol.info/index.php/SAARCT B/article/view/16926
12. Madiba S, Mokgatle M. Fear of stigma , beliefs, and knowledge about HIV are barriers to early access to HIV testing and disclosure for perinatally infected children and adolescents in rural communities in South Africa Fear of stigma, beliefs , and knowledge about HIV are bar. South African Fam Pract [Internet]. 2017;6190(May):1-7. Available from: http://doi.org/10.1080/20786190.2017.1329 489

13. Gyamfi E, Okyere P, Enoch A, Appiahbrempong E. Prevalence of , and barriers to the disclosure of HIV status to infected children and adolescents in a district of Ghana. 2017;1-8.

14. Oberdorfer P, Puthanakit T, Louthrenoo O, Charnsil C, Sirisanthana V, Sirisanthana T. Disclosure of HIV/AIDS diagnosis to HIVinfected children in Thailand. J Paediatr Child Health. 2006;42[5]:283-8.

15. Vaz LME, Maman S, Eng E, Barbarin OA, Tshikandu T, Behets F. Patterns of disclosure of HIV status to infected children in a Sub-Saharan African setting. J Dev Behav Pediatr. 2011;32[4]:307-15.

16. Nilesh T, Gadhavi RN, Pradip D, Ushma B, Samir B, Nisarg P. Sociodemographic profile and health status of children living with HIV-AIDS attached to an NGO (ADHAR) of Ahmedabad city. Int J Med Sci Public Heal. 2015;4[6]:773-6.

17. Anyabolu HC, Adejuyigbe EA, Adeodu OO, Access O, Anyabolu HC, Adejuyigbe EA, et al. Undernutrition and anaemia among HAART-naïve HIV infected children in IleIfe, Nigeria: A case-controlled, hospital based study. Pan Afr Med J. 2014;18:1-8.

18. Lorenz R, Grant E, Muyindike W, Maling S, Card C, Henry C, et al. Caregivers' attitudes towards HIV testing and disclosure of HIV status to at-risk children in rural Uganda. PLoS One. 2016;11[2]:1-22.

19. A. Binagwaho, I. Murekatete, A. Rukundo, P. Mugwaneza, R. Hinda, A. Lyambabaje, 
J.D. Bizimana, C.M. Wagner, G. Muriisa, J. Muita, V. Mutabazi, J.P. Nyemazi, S. Nsanzimana CK. Original Article FACTORS ASSOCIATED WITH DISCLOSURE OF HIV STATUS AMONG HIV-. Rwanda Med J. 2012;69(September):9-15. 